\title{
Curcumin inhibits hepatocellular carcinoma growth by targeting VEGF expression
}

\author{
ZIRONG PAN $^{1 *}$, JIANMIN ZHUANG $^{1 *}$, CHENGHONG JI $^{1}$, ZHEZHEN CAI $^{1}$, \\ WEIJIA LIAO $^{1}$ and ZHENGJIE HUANG ${ }^{2}$
}

\author{
${ }^{1}$ Department of General Surgery, Xiamen Haicang Hospital, Xiamen, Fujian 361026; ${ }^{2}$ Department of \\ Gastrointestinal Surgery, The First Affiliated Hospital of Xiamen University, Xiamen, Fujian 361003, P.R. China
}

Received May 16, 2017; Accepted December 13, 2017

DOI: $10.3892 / \mathrm{ol} .2018 .7988$

\begin{abstract}
Morbidity and mortality owing to hepatocellular carcinoma (HCC), the most common primary liver cancer, has increased in recent years. Curcumin is a polyphenol compound that has been demonstrated to exert effective antiangiogenic, anti-inflammatory, antioxidant, and antitumor effects. However, its clinical effects in $\mathrm{HCC}$ remain elusive. The main aim of the present study was to determine the antiangiogenic effects of curcumin in HCC. H22HCC cells were treated with different concentrations of curcumin in vitro. In addition, a mouse xenograft model was used and analyzed for expression levels of vascular endothelial growth factor (VEGF) protein and proteins of the phosphoinositide 3-kinase (PI3K)/AKT serine/threonine kinase 1 (AKT) signaling pathway. Curcumin treatment inhibited $\mathrm{H} 22$ cell proliferation and promoted H22 cell apoptosis in a dose-dependent manner in vitro. In addition, curcumin treatment inhibited tumor growth in vivo at the concentrations of 50 and $100 \mathrm{mg} / \mathrm{kg}$. Furthermore, curcumin treatment significantly decreased VEGF expression and PI3K/AKT signaling. The present findings demonstrated that curcumin inhibited HCC proliferation in vitro and in vivo by reducing VEGF expression.
\end{abstract}

Correspondence to: Professor Zhengjie Huang, Department of Gastrointestinal Surgery, The First Affiliated Hospital of Xiamen University, 55 Zhenhai Road, Xiamen, Fujian 361003, P.R. China E-mail: huangzhengjie@xmu.edu.cn

*Contributed equally

Abbreviations: HCC, hepatocellular carcinoma; VEGF, vascular endothelial growth factor; CCK-8, Cell Counting Kit-8; FITC, fluorescein isothiocyanate; HRP, horseradish peroxidase; PI, propidium iodide

Key words: curcumin, hepatocellular carcinoma, vascular endothelial growth factor, anti-angiogenic, chemotherapy, polyphenol compound

\section{Introduction}

Hepatocellular carcinoma (HCC) is the most common primary liver cancer and has been the third most common cause of death from cancer globally in recent years $(1,2)$. Several clinical protocols, including conventional chemotherapy, liver transplantation, surgical resection, radio frequency ablation, and transcatheter arterial chemoembolization, have been used to treat HCC $(2,3)$. However, these treatments are often not effective, as indicated by frequent recurrence and low objective response rates (4). Therefore, it is necessary to develop novel effective and safe therapeutic agents in order to improve the efficacy of HCC treatment.

It has been demonstrated that angiogenesis is involved in the progression of human HCC and that angiogenesis is a process that serves a significant role in the aggressiveness of HCC (5). Angiogenesis is induced when hepatic stellate cells and tumor inflammatory cells start to release factors such as vascular endothelial growth factor (VEGF) (6). VEGF is the strongest vasoactive factor and induces the formation of new capillaries from nearby normal existing ones, thereby promoting tumor growth and tumor stroma formation (7). Therefore, VEGF has an important role in the occurrence and development of HCC and treatment strategies for liver cancer by targeting VEGF have become a hot spot.

Curcumin is a polyphenol compound extracted from the rhizomes of Curcuma longa that has been demonstrated to exert effective antiangiogenic, anti-inflammatory and antioxidant effects (8-10). Curcumin exerts antitumor effects in several types of cancer, including hepatic carcinoma, by modulating tumor growth factor- $\beta$, protein kinase $\mathrm{B}$, and caspase- 3 expression (11-14). However, the antiangiogenic effect of curcumin by VEGF in HCC remains obscure. To explore this, the present study examined the antitumor effect of curcumin in HCC. The results demonstrated that curcumin inhibited HCC proliferation in vitro and in vivo by inhibiting VEGF expression and the phosphoinositide 3-kinase (PI3K)/AKT serine/threonine kinase 1 (AKT) signaling pathway.

\section{Materials and methods}

Reagents. Curcumin was purchased from Sigma-Aldrich (Merck KGaA, Darmstadt, Germany). A Cell Counting 
Kit-8 (CCK-8) was purchased from Dojindo Molecular Technologies, Inc. (Kumamoto, Japan). An Annexin V/fluorescein isothiocyanate (FITC) kit was purchased from Vazyme Biotech Co., Ltd. (Nanjing, China). VEGF antibodies (cat no. sc-7269), used for western blotting and immunohistochemistry, were purchased from Santa Cruz Biotechnology, Inc. (Dallas, TX, USA). PI3K (cat no. ab151549) and AKT (cat no. ab38449) antibodies were purchased from Abcam (Cambridge, USA). The polymer horseradish peroxidase (HRP) detection systems, used for immunohistochemistry and western blotting, were purchased from Zhongshan Golden Bridge Biotechnology Co., Ltd (Beijing, China) and Cellular Signaling Technology (Danvers, MA). Recombinant human VEGF (rhVEGF) was from R\&D Systems, Inc. (Minneapolis, MN, USA).

Cell culture. The H22 HCC cell line was purchased from the Cell Bank of Type Culture Collection of the Chinese Academy of Sciences, Shanghai Institute of Cell Biology, Chinese Academy of Sciences (Shanghai, China) and cultured in Dulbecco's modified Eagle's medium supplemented with $10 \%$ fetal calf serum (Hyclone; GE Healthcare Life Sciences, Logan, UT, USA), $100 \mathrm{U} / \mathrm{ml}$ penicillin, and $100 \mu \mathrm{g} / \mathrm{ml}$ streptomycin in a humidified incubator at $37^{\circ} \mathrm{C}$ with $5 \% \mathrm{CO}_{2}$.

Animals. Nude male mice (4-5 weeks old) were purchased from the Model Animal Research Center of Nanjing University (Nanjing, China) and kept under controlled conditions with a 12-h light/dark cycle with access to food and water ad libitum. All animal work was conducted in compliance with guidelines for ethical animal research and approved by the Animal Ethics Committee of Xiamen University (Xiamen, China).

Cell viability assay. $\mathrm{H} 22$ cells were treated with different concentrations of curcumin $(0,5,10,20,40$ and $80 \mu \mathrm{m})$ for 12,24 , or $48 \mathrm{~h}$. In other experiments, H22 cells were stimulated by VEGF $(20 \mathrm{ng} / \mathrm{ml})$ for $24 \mathrm{~h}$ in serum-free medium, and curcumin $(20,40$, and $80 \mu \mathrm{m})$ was added at the same time. Thereafter, a CCK-8 assay was used to determine cell viability, as per the manufacturer's protocol.

Apoptosis assay. $\mathrm{H} 22$ cells were treated with different concentrations of curcumin $(0,20,40$, and $80 \mu \mathrm{m})$ for $24 \mathrm{~h}$. Apoptosis was quantitatively measured by Annexin V/propidium iodide (PI) double staining which was carried out at room temperature for $2 \mathrm{~h}$. Cell apoptosis was evaluated using FACSVerse ${ }^{\mathrm{TM}}$ (Beckman Coulter, Inc., Brea, CA, USA), and data were analyzed using FlowJo V10 (Flowjo LLC, Ashland, OR, USA).

Tumor xenografts and in vivo curcumin treatment. $\mathrm{H} 22$ cells $\left(2 \times 10^{5}\right)$ were subcutaneously injected into nude mice (4-5 weeks old, $n=15$ ). Seven days after tumor cell inoculation, the mice were randomly divided into three groups of five and treated with vehicle $(0.1 \%$ DMSO) or curcumin at a dose of $50,100 \mathrm{mg} / \mathrm{kg}$ daily for two weeks. At day 24 , the tumors were removed and weighed.

Histopathology. Tumor tissues from the xenograft model mice were collected and fixed in formalin at $4^{\circ} \mathrm{C}$ for $48 \mathrm{~h}$, decalcified in $10 \%$ ethylenediamine tetraacetic acid, and embedded in paraffin for histopathological analysis. Serial paraffin sections $(5 \mu \mathrm{m})$ were stained with hematoxylin and eosin at room temperature for $10 \mathrm{~min}$.

Immunohistochemistry. Tumor samples were fixed with formalin at $4^{\circ} \mathrm{C}$ for $48 \mathrm{~h}$, embedded in paraffin, and sectioned into $5 \mu \mathrm{m}$ sections. Sections were dewaxed and dehydrated in a descending series of ethanol dilutions: $100 \%$ ethanol (2 times, 2 min each), 95\% ethanol (2 times, 2 min each) and 70\% ethanol (1 time, $2 \mathrm{~min}$ ). Once rehydrated, antigen retrieval was performed using a citrate buffer, and endogenous peroxidase activity was blocked at room temperature for $10 \mathrm{~min}$ using $3.0 \%$ hydrogen peroxide, and the sections were blocked at room temperature for $30 \mathrm{~min}$ using $10 \%$ goat serum, then incubated with the primary antibodies directed against VEGF (1:200) at $4^{\circ} \mathrm{C}$ overnight. Primary antibodies were detected using a horseradish peroxidase-conjugated anti-mouse secondary antibody (1:1,000; cat no. SP-9002; Zhongshan Golden Bridge Biotechnology Co., Ltd) for $30 \mathrm{~min}$ at $37^{\circ} \mathrm{C}$. Following rinsing with PBS three times, the sections were exposed for $7 \mathrm{~min}$ to diaminobenzidine $(\mathrm{DAB})+$ chromogen, then dehydrated in ethanol and xylene and mounted onto glass slides. The staining intensity and average percentage of positive cells were assayed for 10 independent fields using a light microscope at a magnification of $\mathrm{x} 400$.

Western blot analysis. Tumor tissues were washed with PBS three times, then ground and lysed in RIPA cell lysis buffer (1\% NP-40, 0.5\% sodium deoxycholate, $0.1 \%$ SDS in PBS). Following centrifugation at a speed of $14,000 \mathrm{x} \mathrm{g}$ for $5 \mathrm{~min}$ at $4^{\circ} \mathrm{C}$, the supernatants were kept frozen at $-80^{\circ} \mathrm{C}$ until use. Protein concentrations were measured using the BCA protein quantification Kit (Beyotime, Haimen, China) according to the manufacturer's protocol. A total of $50 \mu \mathrm{g}$ of denatured protein was separated using 10\% SDS-PAGE and transferred onto polyvinylidene fluoride membranes. The membranes were blocked with $10 \%$ non-fat milk at room temperature for $1 \mathrm{~h}$ and then incubated with primary antibodies for VEGF, PI3K, AKT (1:1,000) and mouse monoclonal anti- $\beta$-actin $(1: 5,000)$ at $4^{\circ} \mathrm{C}$ overnight, followed by incubation with appropriate HRP-conjugated anti-mouse secondary antibodies (1:1,000; cat nos. 7074 and 7076; Cell Signaling Technology, Inc., Danvers, MA, USA) for $1 \mathrm{~h}$ at room temperature. Protein signals were detected using the BeyoECL plus kit (Beyotime Institute of Biotechnology, Haimen, China) according to the manufacturer's protocol. Finally, the densities of the bands were quantified using Image J software (version 1.38; National Institutes of Health, Bethesda, MD, USA) (15). Equivalent protein loading and transfer efficiency were verified by staining for $\beta$-actin.

Reverse transcription-quantitative polymerase chain reaction (RT-qPCR). Total RNA from the tumor tissues was isolated using TRIzol (Takara Bio, Inc., Otsu, Japan), according to the manufacturer's protocol. RETROscript ${ }^{\mathrm{TM}}$ Reverse Transcription kit (Thermo Fisher Scientific, Inc., Waltham, MA, USA) and $1 \mu \mathrm{g}$ RNA were used for cDNA synthesis. SYBR Green One-Step qRT-PCR kit (Thermo Fisher Scientific, Inc.) and a 7900 HT Fast Real-Time PCR System (Applied Biosystems; Thermo Fisher Scientific, Inc.) were 
used for qPCR. Data were normalized to the internal control GAPDH and presented as an expression fold change using the $2^{-\Delta \Delta C q}$ method (16). Thermocycling conditions were as follows: $95^{\circ} \mathrm{C}$ for $3 \mathrm{~min}$, followed by 40 cycles at $94^{\circ} \mathrm{C}$ for $30 \mathrm{sec}, 60^{\circ} \mathrm{C}$ for $30 \mathrm{sec}$ and $72^{\circ} \mathrm{C}$ for $60 \mathrm{sec}$. The gene-specific primers were selected according to the literature. The primers were synthesized by Sangon Biological Engineering Technology Services Co., Ltd. (Shanghai, China). The primer sequences were as follows: PI3K, forward 5'-CGTTTCTGCTTTGGGACAAC-3' and reverse 5'-CCTGATGATGGTGGAG-3'; AKT, forward 5'-TGAGAGAAGCCACGCTGTC-3' and reverse 5'-CGG AGAACAAACTGGATGAA-3'; VEGF, forward 5'-TAGACG TTCCCTGCCAGCAA-3' and reverse 5'-AGCATCCGAGGA AAACATAAAATCTT-3'; and GAPDH, forward 5'-AAC GGATTTGGTCGTATTGGG-3' and reverse 5'-TCGCTC CTGGAAGATGGTGAT-3'.

Statistical analysis. Data were expressed as mean \pm standard deviation. Statistics were presented in Prisms 6.1 software (GraphPad Software, Inc., La Jolla, CA, USA). All data were analyzed using one-way analysis of variance followed by the Tukey test. $\mathrm{P}<0.05$ was considered to indicate a statistically significant difference.

\section{Results}

Curcumin inhibits proliferation and induces apoptosis in HCC cells. To investigate the inhibitory effect of curcumin on HCC cells, a CCK-8 assay was performed to detect cell viability in vitro. The results demonstrated that curcumin inhibited $\mathrm{H} 22$ cell viability in a dose-dependent manner, and particularly at a very high dose of $80 \mu \mathrm{M}(\mathrm{P}<0.01$; Fig. 1A). In addition, Annexin V/PI staining was performed to determine the apoptosis rate of $\mathrm{H} 22$ cells. Curcumin treatment significantly induced $\mathrm{H} 22$ cell apoptosis, especially at concentrations of 40 and $80 \mu \mathrm{m}(\mathrm{P}<0.05$ and $\mathrm{P}<0.01$ compared with untreated control respectively; Fig. 1B).

Curcumin inhibits tumor growth in a xenograft model in vivo. To further explore the anticancer activities of curcumin in vivo, a xenograft model was established in mice using $\mathrm{H} 22$ cells and treated with 50 or $100 \mathrm{mg} / \mathrm{kg}$ of curcumin by intragastric administration for two weeks. The results demonstrated that curcumin treatment resulted in a dramatic inhibition of H22 xenograft tumor growth compared with the vehicle-treated control group, particularly at a very high dose $(50 \mathrm{mg} / \mathrm{kg}, \mathrm{P}<0.05 ; 100 \mathrm{mg} / \mathrm{kg}, \mathrm{P}<0.01 ; \mathrm{n}=5$; Fig. 2A). The tumor weight in the curcumin-treated groups were significantly decreased compared with the vehicle-treated control group $(50 \mathrm{mg} / \mathrm{kg}, \mathrm{P}<0.05 ; 100 \mathrm{mg} / \mathrm{kg}, \mathrm{P}<0.01 ; \mathrm{n}=5$; Fig. 2B). Furthermore, histopathological analysis indicated that tumor cells in the curcumin-treated groups were visibly sparser compared with those in the vehicle-treated control group (Fig. 2C).

Curcumin inhibits VEGF protein expression and PI3K/AKT signaling in vivo. Next, the mechanisms by which curcumin exerts its antitumor effect in vivo were explored. Immunohistochemistry analysis indicated that curcumin treatment impaired the expression of VEGF in the tumor tissues
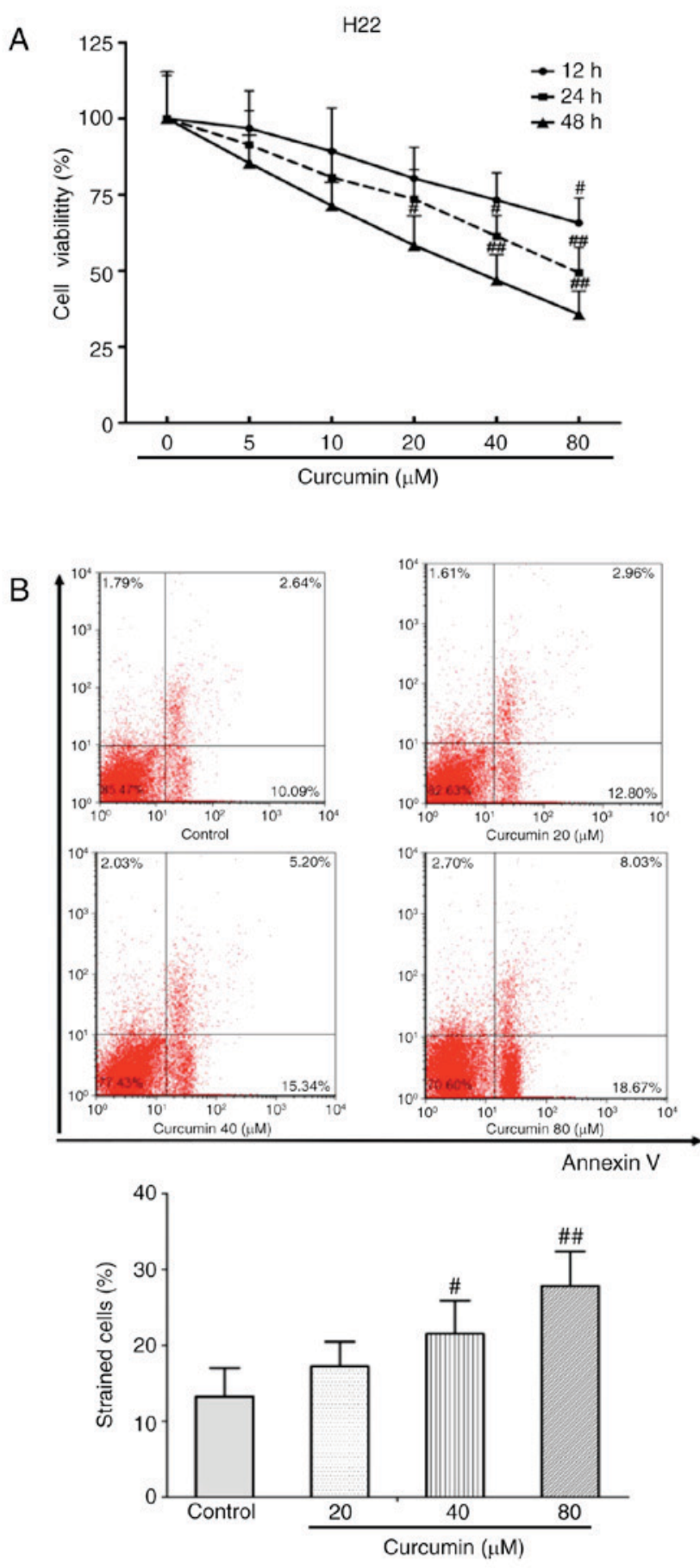

Figure 1. Curcumin inhibits proliferation and induces apoptosis in hepatocellular carcinoma cells. (A) Cell viability of $\mathrm{H} 22$ cells treated with different concentrations of curcumin were detected at 12,24 and $48 \mathrm{~h}$. (B) Representative plots and quantification of apoptosis rates in $\mathrm{H} 22$ cells treated with different concentrations of curcumin $(20,40$ and $80 \mu \mathrm{M})$. Data are expressed as the mean \pm standard deviation. ${ }^{\#} \mathrm{P}<0.05$ and ${ }^{\# \#} \mathrm{P}<0.01$ compared with control. Each experiment was repeated three times.

obtained from the tumor-bearing mice in a dose dependent manner $(50 \mathrm{mg} / \mathrm{kg}, \mathrm{P}<0.05 ; 100 \mathrm{mg} / \mathrm{kg}, \mathrm{P}<0.01 ;$ Fig. 3). Previous studies have implicated that VEGF expression is mediated via PI3K/AKT signaling pathway. Results from the western blot analysis of the tumor tissues indicated that protein expression levels of PI3K and AKT were inhibited following curcumin treatment (Fig. 3). In addition, the mRNA expression levels of 

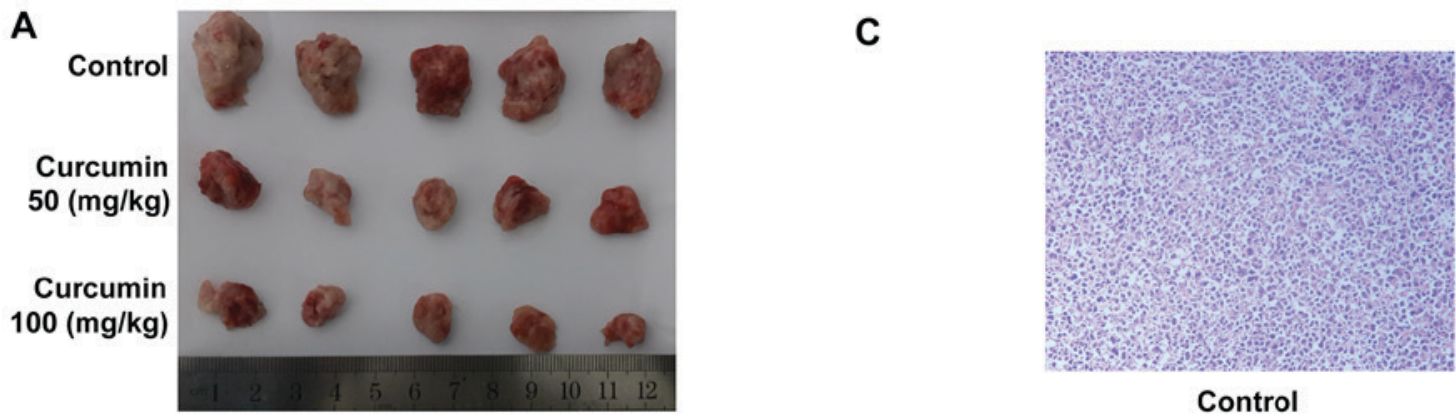

Control

B

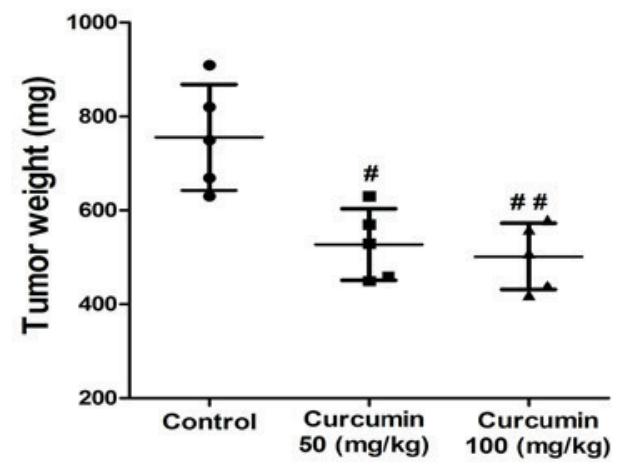

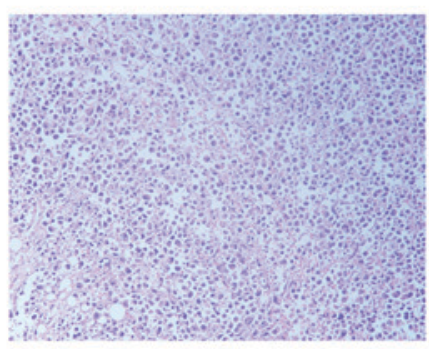

Curcumin $50(\mathrm{mg} / \mathrm{kg})$

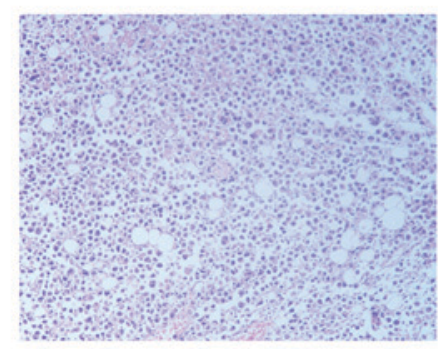

Curcumin $100(\mathrm{mg} / \mathrm{kg})$

Figure 2. Curcumin inhibits tumor growth in a xenograft model in vivo. (A) Images of tumors in the control group and in the 50 and $100 \mathrm{mg} / \mathrm{kg}$ curcumin-treated groups ( $\mathrm{n}=5$ per group). (B) Tumor weight measurements in the control group and the 50 and $100 \mathrm{mg} / \mathrm{kg}$ curcumin-treated groups ( $\mathrm{n}=5 \mathrm{per}$ group). (C) Representative images (at a magnification of $\mathrm{x} 400$ ) from histopathology analysis of the control group and the 50 and $100 \mathrm{mg} / \mathrm{kg}$ curcumin-treated groups. ${ }^{\#} \mathrm{P}<0.05$ and ${ }^{\# \#} \mathrm{P}<0.01$ compared with control.

A

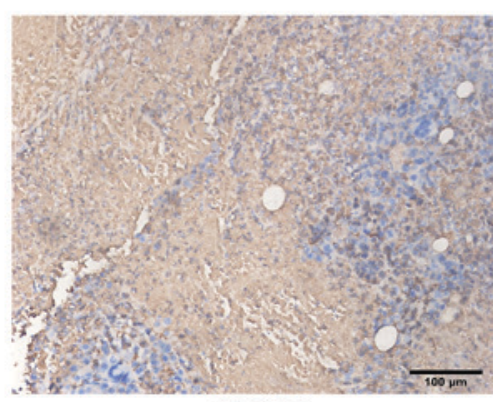

Control

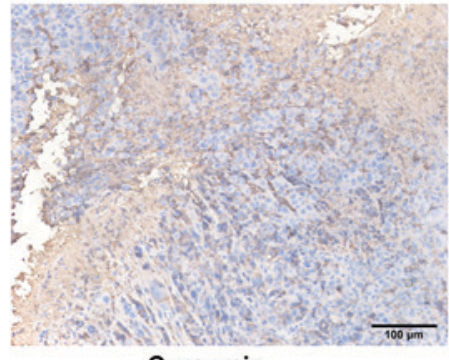

Curcumin $50(\mathrm{mg} / \mathrm{kg})$

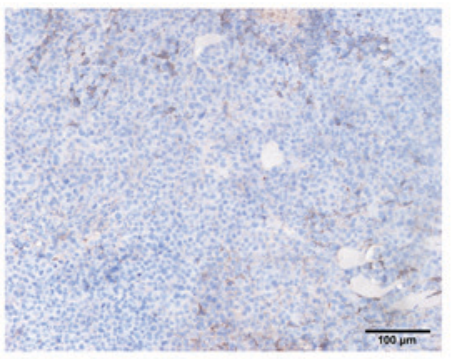

Curcumin $100(\mathrm{mg} / \mathrm{kg})$
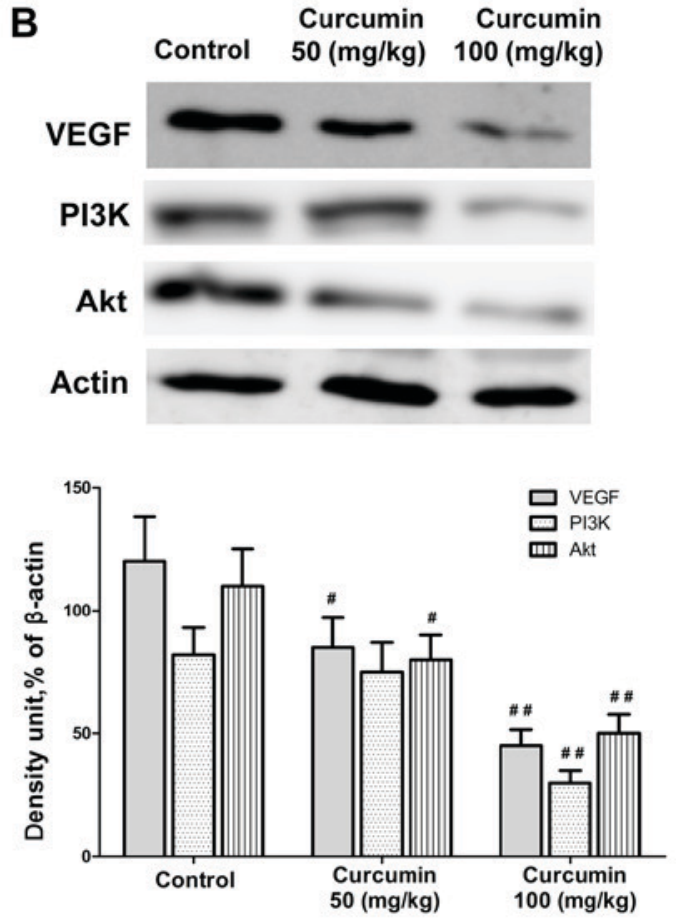

Figure 3. Curcumin inhibits VEGF protein expression and PI3K/AKT signaling in vivo. (A) Immunohistochemistry images of VEGF protein expression levels in the control group and the 50 and $100 \mathrm{mg} / \mathrm{kg}$ curcumin-treated groups. (B) Representative western blot images and quantification of VEGF and PI3K/AKT protein expression levels in the control group and the 50 and $100 \mathrm{mg} / \mathrm{kg}$ curcumin-treated groups. $\beta$-actin served as an internal control. ${ }^{\#} \mathrm{P}<0.05$ and ${ }^{\# \#} \mathrm{P}<0.01$ compared with control. VEGF, vascular endothelial growth factor; PI3K, phosphoinositide 3-kinase; AKT, AKT serine/threonine kinase 1.

VEGF, PI3K and AKT were also significantly downregulated by curcumin treatment (Fig. 4). These findings suggested that the anticancer activities of curcumin in vivo were associated with the downregulation of VEGF expression in human HCC cells, and most likely mediated through the PI3K/AKT signaling pathway. 


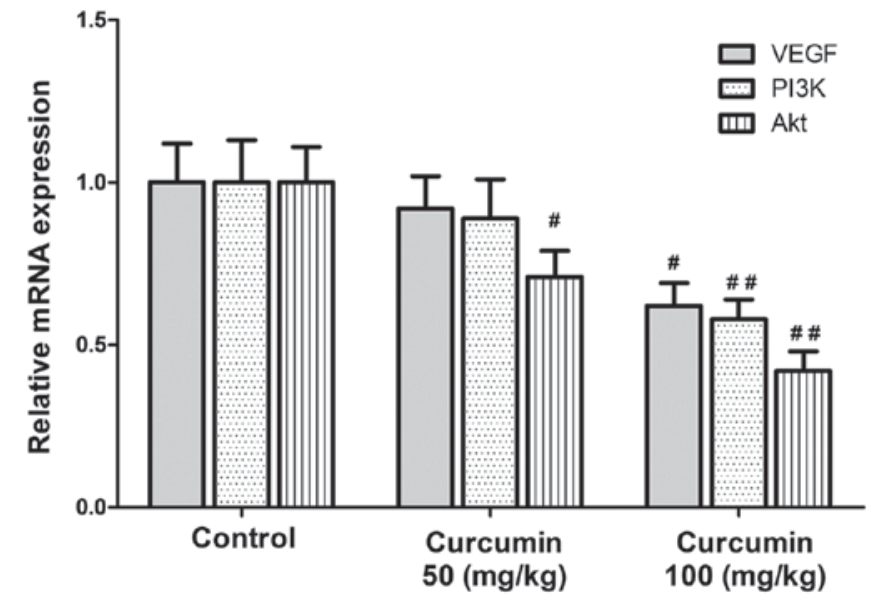

Figure 4. mRNA expression of VEGF and PI3K/AKT in the control group and the 50 and $100 \mathrm{mg} / \mathrm{kg}$ curcumin-treated groups. ${ }^{\#} \mathrm{P}<0.05$ and ${ }^{\# \#} \mathrm{P}<0.01$ compared with control. VEGF, vascular endothelial growth factor; PI3K, phosphoinositide 3-kinase; Akt, AKT serine/threonine kinase 1.

VEGF mediates the curcumin effect on HCC cell viability. Finally, in order to examine whether VEGF mediates the curcumin effect in inhibiting HCC cell viability, recombinant human VEGF (rhVEGF) was used. Compared with different concentrations of curcumin-treated cells, rhVEGF-treated group caused an increase in HCC cell growth (Fig. 5). Curcumin treatment resulted in a significant reduction of VEGF-induced proliferation $(\mathrm{P}<0.01$; Fig. 5).

\section{Discussion}

In the present study, proliferation and apoptosis of $\mathrm{H} 22$ cells were detected with CCK-8 assay and Annexin V/PI double staining, respectively, following treatment with different concentrations of curcumin. The results indicated that curcumin significantly inhibited cell growth and induced apoptosis of $\mathrm{H} 22$ cells in a dose-dependent manner in vitro. In addition, curcumin treatment significantly inhibited tumor growth, and significantly reduced VEGF protein expression and PI3K/AKT signaling, in vivo in a xenograft mouse model.

$\mathrm{HCC}$ is the primary form of liver cancer and represents the sixth most common cancer worldwide. As part of its multifaceted molecular pathogenesis, angiogenesis has a significant role in the aggressiveness of $\operatorname{HCC}(17,18)$. Therefore, improved knowledge of oncogenic processes and the signaling pathways that regulate angiogenesis progression are important and drive the development of molecularly targeted therapies (6).

Curcumin, a major constituent of $C$. longa, has been demonstrated to act as a potential therapeutic agent in diseases like cancer involving a variety of biological mechanisms, including cell cycle regulation, induction of apoptosis, inhibition of metastasis, oncogene expression, and tumorigenesis $(8,19-21)$. A potent inhibition by curcumin of the transcription factor nuclear factor $(\mathrm{NF})-\kappa \mathrm{B}$, and the resultant downstream gene products, including MYC proto-oncogene (c-myc), BCL2 apoptosis regulator

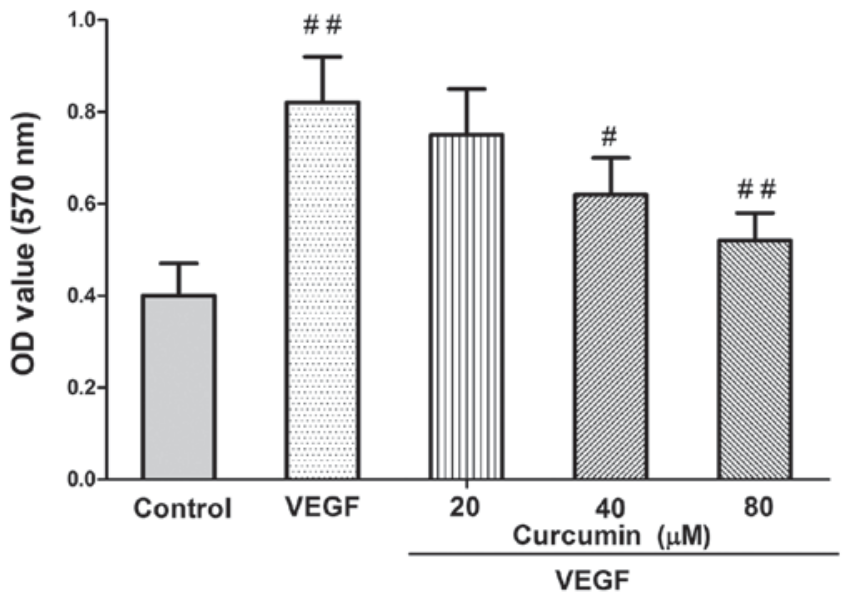

Figure 5. VEGF enhances HCC viability. Cell viability of H22 cells treated with recombinant human VEGF and different concentrations of curcumin was measured in vitro. ${ }^{\#} \mathrm{P}<0.05$ and ${ }^{\# \#} \mathrm{P}<0.01$ compared with the group treated with $20 \mu \mathrm{M}$ curcumin. VEGF, vascular endothelial growth factor; OD, optical density. Each experiment was repeated three times.

(Bcl-2), nitric oxide synthase, cyclooxygenase-2, cyclin D1, matrix metallopeptidase9, tumor necrosis factor- $\alpha$, and interleukins, was reported to be effective against most types of cancer (22). In addition, curcumin has been reported to exert its tumor suppressing effect via an antiangiogenic effect (23). However, it remains unknown whether curcumin could be a new therapeutic agent targeting HCC due to its antiangiogenic mechanism. In the present study, curcumin significantly inhibited HCC growth in vitro and in vivo by targeting VEGF expression and the PI3K/AKT signaling pathway.

One of the major limitations regarding the present work is that the exact mechanism by which curcumin targets VEGF in HCC cells remains unclear. Therefore, it will be very important to perform additional studies in the future to explore this specific mechanism.

The present results are the first to demonstrate that curcumin inhibited HCC growth in vitro and in vivo through targeting VEGF expression, and may provide important information about curcumin as a potential therapeutic agent for the treatment of HCC. However, further in vitro and in vivo studies will be needed to understand the exact mechanism of curcumin targeting HCC.

\section{Acknowledgements}

The present study was supported by the Project of Xiamen Haicang District Scientific and Technological Plan (grant no. 350205Z54011), Medical Innovations Topic in Fujian Province (grant no. 2012-CXB-29), the Project of Xiamen Scientific and Technological Plan (grant no. 3502Z20174023) and the Science and Technology Project of Natural Science Foundation of Fujian Province (grant no. 2016J01639).

\section{Competing interests}

The authors declare that they have no competing interests. 


\section{References}

1. Chen W, Zheng R, Baade PD, Zhang S, Zeng H, Bray F, Jemal A Yu XQ and He J: Cancer statistics in China, 2015. CA Cancer J Clin 66: 115-132, 2016.

2. Li M, Zhang W, Wang B, Gao Y, Song Z and Zheng QC: Ligand-based targeted therapy: A novel strategy for hepatocellular carcinoma. Int J Nanomedicine 11: 5645-5669, 2016.

3. Forner A, Reig ME, de Lope CR and Bruix J: Current strategy for staging and treatment: The BCLC update and future prospects. Semin Liver Dis 30: 61-74, 2010.

4. Peters GJ and Honeywell RJ: Drug transport and metabolism of novel anticancer drugs. Expert Opin Drug Metab Toxicol 11: 661-663, 2015.

5. Berretta M, Rinaldi L, Di Benedetto F, Lleshi A, De Re V, Facchini G, De Paoli P and Di Francia R: Angiogenesis inhibitors for the treatment of hepatocellular carcinoma. Front Pharmacol 7: 428, 2016

6. Hanahan D and Folkman J: Patterns and emerging mechanisms of the angiogenic switch during tumorigenesis. Cell 86: 353-364, 1996.

7. Di J, Gao K, Qu D, Yang J and Zheng J: Rap2B promotes angiogenesis via PI3K/AKT/VEGF signaling pathway in human renal cell carcinoma. Tumour Biol 39: 1010428317701653, 2017.

8. Jurenka JS: Anti-inflammatory properties of curcumin, a major constituent of Curcuma longa: A review of preclinical and clinical research. Altern Med Rev 14: 141-153, 2009.

9. Jiao D, Wang J, Lu W, Tang X, Chen J, Mou H and Chen QY: Curcumin inhibited HGF-induced EMT and angiogenesis through regulating c-Met dependent PI3K/Akt/mTOR signaling pathways in lung cancer. Mol Ther Oncolytics 3: 16018, 2016.

10. Haryuna TS, Munir D, Maria A and Bashiruddin J: The antioxidant effect of curcumin on cochlear fibroblasts in rat models of diabetes mellitus. Iran J Otorhinolaryngol 29: 197-202, 2017.

11. Zhang CY, Zhang L, Yu HX, Bao JD and Lu RR: Curcumin inhibits the metastasis of $\mathrm{K} 1$ papillary thyroid cancer cells via modulating E-cadherin and matrix metalloproteinase-9 expression. Biotechnol Lett 35: 995-1000, 2013.

12. Lin J, Deng H, Jin L, Pandey P, Quinn J, Cantin S, Rynkiewicz MJ Gorga JC, Bibbins F, Celatka CA, et al: Design, synthesis, and biological evaluation of peptidomimetic inhibitors of factor XIa as novel anticoagulants. J Med Chem 49: 7781-7791, 2006.

13. Chen WC, Lai YA, Lin YC, Ma JW, Huang LF, Yang NS, Ho CT, Kuo SC and Way TD: Curcumin suppresses doxorubicin-induced epithelial-mesenchymal transition via the inhibition of TGF- $\beta$ and PI3K/AKT signaling pathways in triple-negative breast cancer cells. J Agric Food Chem 61: 11817-11824, 2013.
14. Abouzied MM, Eltahir HM, Abdel Aziz MA, Ahmed NS, Abd El-Ghany AA, Abd El-Aziz EA and Abd El-Aziz HO: Curcumin ameliorate DENA-induced HCC via modulating TGF- $\beta$, AKT, and caspase- 3 expression in experimental rat model. Tumour Biol 36: 1763-1771, 2015.

15. Schneider CA, Rasband WS and Eliceiri KW: NIH Image to Image J: 25 years of image analysis. Nat Methods 9: 671-675, 2012.

16. Livak KJ and Schmittgen TD: Analysis of relative gene expression data using real-time quantitative PCR and the 2(-Delta Delta C(T)) method. Methods 25: 402-408, 2001.

17. Whittaker S, Marais R and Zhu AX: The role of signaling pathways in the development and treatment of hepatocellular carcinoma. Oncogene 29: 4989-5005, 2010.

18. Mogler C, König C, Wieland M, Runge A, Besemfelder E, Komljenovic D, Longerich T, Schirmacher P and Augustin HG: Hepatic stellate cells limit hepatocellular carcinoma progression through the orphan receptor endosialin. EMBO Mol Med 9: 741-749, 2017

19. Hu A, Huang JJ, Jin XJ, Li JP, Tang YJ, Huang XF, Cui HJ, $\mathrm{Xu} \mathrm{WH}$ and Sun GB: Curcumin suppresses invasiveness and vasculogenic mimicry of squamous cell carcinoma of the larynx through the inhibition of JAK-2/STAT-3 signaling pathway. Am J Cancer Res 5: 278-288, 2014.

20. Zhu AX: Systemic therapy of advanced hepatocellular carcinoma: How hopeful should we be? Oncologist 11: 790-800, 2006.

21. Farhangi B, Alizadeh AM, Khodayari H, Khodayari S, Dehghan MJ, Khori V, Heidarzadeh A, Khaniki M, Sadeghiezadeh M and Najafi F: Protective effects of dendrosomal curcumin on an animal metastatic breast tumor. Eur J Pharmacol 758: 188-196, 2015.

22. Kumar P, Kadakol A, Shasthrula PK, Mundhe NA, Jamdade VS, Barua CC and Gaikwad AB: Curcumin as an adjuvant to breast cancer treatment. Anticancer Agents Med Chem 15: 647-656, 2015.

23. Wang Z, Dabrosin C, Yin X, Fuster MM, Arreola A, Rathmell WK, Generali D, Nagaraju GP, El-Rayes B, Ribatti D, et al: Broad targeting of angiogenesis for cancer prevention and therapy. Semin Cancer Biol 35 (Suppl): S224-S243, 2015.

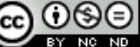

This work is licensed under a Creative Commons Attribution-NonCommercial-NoDerivatives 4.0 International (CC BY-NC-ND 4.0) License. 